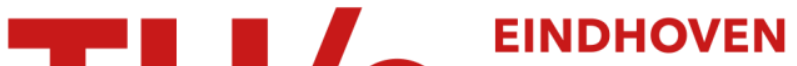 UNIVERSITY OF TECHNOLOGY
}

\section{Adaptive-speed/CAV algorithm in a CD-ROM drive to accomplish high data transfer rate and low power consumption}

Citation for published version (APA):

Stan, S. G., Kempen, van, H., Lin, C. C. S., Yen, M. S. M., \& Wang, W. W. (1998). Adaptive-speed/CAV algorithm in a CD-ROM drive to accomplish high data transfer rate and low power consumption. IEEE Transactions on Magnetics, 34(2), 407-410. https://doi.org/10.1109/20.667777

DOI:

$10.1109 / 20.667777$

Document status and date:

Published: 01/01/1998

Document Version:

Publisher's PDF, also known as Version of Record (includes final page, issue and volume numbers)

\section{Please check the document version of this publication:}

- A submitted manuscript is the version of the article upon submission and before peer-review. There can be important differences between the submitted version and the official published version of record. People interested in the research are advised to contact the author for the final version of the publication, or visit the $\mathrm{DOI}$ to the publisher's website.

- The final author version and the galley proof are versions of the publication after peer review.

- The final published version features the final layout of the paper including the volume, issue and page numbers.

Link to publication

\footnotetext{
General rights

- You may freely distribute the URL identifying the publication in the public portal. follow below link for the End User Agreement:

www.tue.nl/taverne

Take down policy

If you believe that this document breaches copyright please contact us at:

openaccess@tue.nl

providing details and we will investigate your claim.
}

Copyright and moral rights for the publications made accessible in the public portal are retained by the authors and/or other copyright owners and it is a condition of accessing publications that users recognise and abide by the legal requirements associated with these rights.

- Users may download and print one copy of any publication from the public portal for the purpose of private study or research.

- You may not further distribute the material or use it for any profit-making activity or commercial gain

If the publication is distributed under the terms of Article 25fa of the Dutch Copyright Act, indicated by the "Taverne" license above, please 


\title{
Adaptive-Speed/CAV Algorithm in a CD-ROM Drive to Accomplish High Data Transfer Rate and Low Power Consumption
}

\author{
Sorin G. Stan, Henk van Kempen, \\ Chi-Cheng Steve Lin, M.-S. Mason Yen and Wai W. Wang
}

\begin{abstract}
This paper presents an adaptive-speed/CAV algorithm which regulates the disc velocity in a CD-ROM system to accomplish high data throughput (bit rate) during continuous playback and low power consumption during continuous data access. The adaptive-speed profile is based upon quasi-CLV control [1] which allows drive optimization towards both data throughput and access time. The presented algorithm can automatically distinguish between two operating modes - continuous access and continuous playback. By detecting the state of continuous access, the CD-ROM drive switches its spindle-motor loop into a constant angular velocity (CAV) mode, avoiding therefore the acceleration/braking of the motor, and thus reducing the power consumption. By detecting the state of continuous playback, the spindle motor will be set to follow an adaptive-speed profile which is highly optimized for data transfer rate. The software and hardware implementation of the CAV/quasi-CLV switching technique in a CD-ROM system is also described.
\end{abstract}

Keywords - access time, adaptive-speed CD-ROM drive, bit rate, CAV control, CD-ROM, CLV control, data throughput, quasi-CLV control, seek time.

\section{INTRODUCTION}

$\mathrm{T}$ HE performance of a CD-ROM drive is mainly given in terms of data transfer rate, average access time, CPU (central processing unit) utilization, and power consumption. The first two and the latter performance indicators purely characterize the drive itself whilst the CPU utilization measures the processor load on the host computer. The CPU utilization is primarily determined by the datapath firmware and the device driver installed on the host side and it is not of interest for this paper.

In order to optimize the performance of a CD-ROM drive, a trade-off has always been made between high data transfer rate and low access time. However, the need for miniaturization as well as the boost of the drive speeds have triggered the optimization towards power consumption. The current drawn from the power supply can be reduced especially when continuous data access is performed. In this paper, an adequate algorithm is reported which is

Sorin G. Stan and Henk van Kempen are with the Optical Storage Division of Philips Components B.V., Bldg. SFJ-1, P.O. Box 80002, 5600 JB Eindhoven, The Netherlands.

Correspondence E-mail address: stan@iclab.ce.philips.nl

Chi-Cheng Steve Lin, M.-S. Mason Yen and Wai W. Wang are with the Input \& Storage Division of Acer Peripherals, Inc., 157 Shan-Ying Road, Kweishan, Taoyuan 333, Taiwan, R.O.C.

Correspondence E-mail address: WilliamWang@api.com.tw able to automatically distinguish between continuous playback and continuous access so that the drive performance can be optimized separately for high data transfer rate, low access time and low power consumption, respectively.

\section{CLV, CAV AND QUASI-CLV MOTOR CONTROL}

As the data on a CD-ROM dise is uniformly distributed along a continuous spiral, the constant linear velocity (CLV) control remains the only way to drive the spindle motor such that a maximum average data transfer rate can be achieved. However, it has been shown [1] that pure CLV becomes obsolete when the pickup head moves very fast from one location to another along the disc radius. Alternatively, there are two solutions: either (i) implementing a full constant angular velocity (CAV) motor control or (ii) controlling the spindle motor within a quasi-CLV loop, as reported in the mentioned paper.

When compared with CAV control, the quasi-CLV solution does not worsen the averaged data transfer rate of the system whilst still preserving the access performance of the CAV mode. Moreover, the quasi-CLV can serve as basic control loop for an adaptive-speed CD-ROM drive [1]. Such a drive features a real-time adjustment of the disc rotational frequency dependent on the read-out position ${ }^{1}$ of the optical pickup unit. By adequately choosing the speed profile between the inner and outer disc radii, an optimal trade-off between data throughput and access time can be achieved.

\section{The Adaptive-Speed/CAV Trade-OfF}

The quasi-CLV control will always brake or accelerate the spindle motor while seeking outwards, respectively during inward-oriented seeks ${ }^{2}$. This behavior is nothing but a consequence of using the real disc speed to drive the motor and compare it with a fixed reference.

An adaptive-speed CD-ROM system will further adjust this reference as dependent on the subcode timing. How-

\footnotetext{
${ }^{1}$ This position is indicated by the subcode information which is recorded along with the user data and defines the time-position of a data cluster along the disc spiral, at $1 \mathrm{X}$ speed. The finest division of the subcode timing indicates $1 / 75$ seconds and the cluster amounts for 2352 user bytes.

${ }^{2}$ In general, for a disc-based storage system, the servo is said to perform a seek when the radial control is directed to place the read head on a track different from the present one [2].
} 
ever, during continuous data access, the motor speed heither arrives at a steady-state nor reaches its target quasiCLV velocity. Since the motor driver is driven in saturation, additional power dissipation will take place.

At high and very high disc speeds, e.g. 20X, 24X, or $30 \mathrm{X}$, the heat generated in the spindle-motor loop (namely in the motor driver and motor itself) reaches excessive values. The power dissipation becomes therefore an important design parameter. As a matter of fact, we are not interested in maximizing the data transfer rate during continuous data access. It follows that a less aggressive motor control should be employed during this operating mode and the best crioice is still the CAV.

Based upon the above discussions, the essence of CDROM performance optimization presented within this paper consists of 1) adaptive-speed profile based on quasi$\mathrm{CLV}$ control during continuous playback and 2) CAV mode during continuous seek. The adaptive-speed profile should be optimized such that a maximum of the average bit rate is obtained while reading out data from the inside to the outside of the disc. An example of such optimization which leads to a cubic overspeed ${ }^{3}$ profile is presented in [3]. Further, the adaptive-speed profile can also be refined for a short sequence of data seeks when the CAV control does not need being switched on.

\section{Circuit Functional Principle}

The equipment used in this study is a 20X CD-ROM drive made by Acer Peripherals, Inc., which is based on Philips key components. The block diagram of the spindle motor control loop is illustrated in Fig. 1. For a long se-

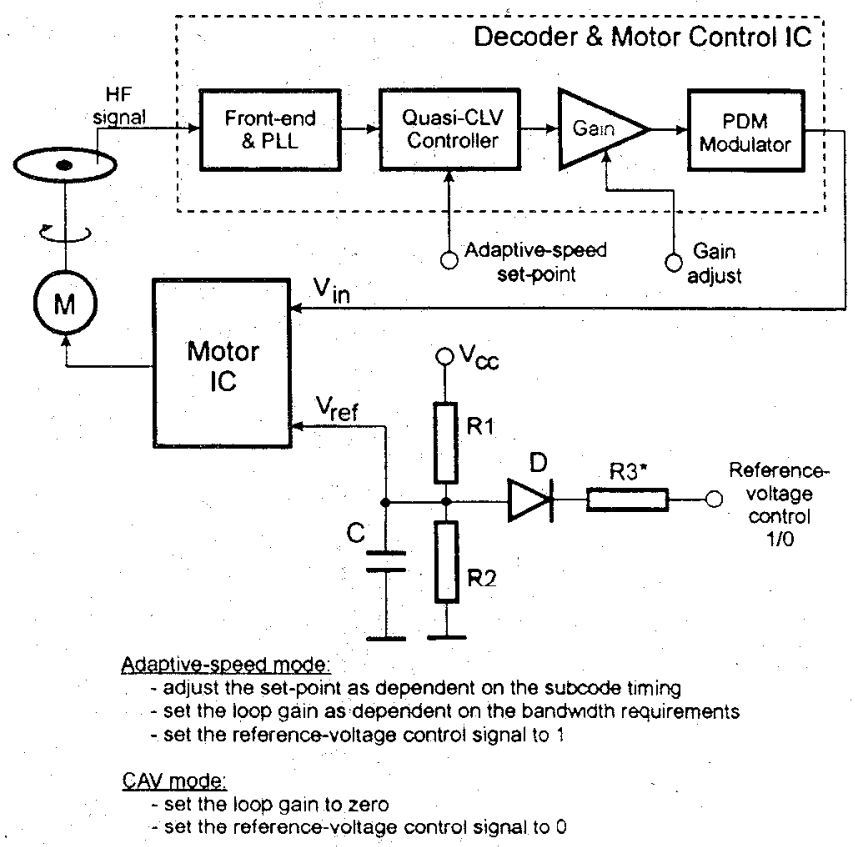

Fig. 1. Block diagram and functionality of a combined adaptivespeed (quasi-CLV)/CAV controller.

\footnotetext{
${ }^{3}$ The overspeed $N$ is defined as the ratio between the linear velocity of the disc measured at the read-out radial position and the linear velocity $v_{a}=1.3 \pm 0.1 \mathrm{~m} / \mathrm{s}$ of the recorded data.
}

quence of seeks when the CAV control loop is desired, the motor will be driven by a tacho circuitry or merely by an open-loop voltage. Due to heavy competition within the CD-ROM industry, the open-loop control is a preferred solution as long as the margin for overspeed tolerance can be maintained.

\section{FirmWare AlgorithM For SWITCHING BETWEEN ADAPTIVE-SPEED AND CAV}

In order to detect the continuous-seek operating mode of the drive, a suitable algorithm should be provided. This algorithm will interfere with the motor control loop, switching on the CAV mode if necessary. Nevertheless, a certain convention should also be agreed upon such that a clear separation can be made between different repetitive seekplayback patterns. Any other operating modes which do not fulfill the requirements for continuous seek (e.g. short seeks or continuous playback) are flagged accordingly and the adaptive-speed motor control is kept active.

The detection mechanism monitors some variables related both to the seek length and to the number of seeks performed within a certain time. The number of long-range seeks is recorded by a counter and, if enough seeks have been performed within a given time interval, the counter will be reset and the CAV mode will be switched on. In addition, depending on whether or not a read command has been issued by the host system, the algorithm keeps either the CAV mode or the adaptive-speed mode activated. This decision depends upon not only the size of the available empty buffer (which can still be used by the data path at that particular moment) but also on the amount of data to be transferred towards the host system. This approach ensures an optimized flow of data through the host interface by monitoring the data flow coming from the bit engine. The disc speed can thus be regulated and better correlated with a given strategy for the buffer management. This algorithm is implemented at the data-path firmware level and its corresponding flow chart is illustrated in Fig. 2 and Fig. 3.

\section{EXPERIMENTAL RESULTS}

The efficiency of the proposed algorithm has been tested by monitoring the heat dissipation in the spindle motor and the power consumption of the motor driver. Table 1 shows that the power dissipation is significantly reduced when the $\mathrm{CAV}$ motor control is activated during continuous access which leads to a lower temperature of the spindle motor.

\begin{tabular}{|c|c|c|}
\hline $\begin{array}{c}\text { Measured } \\
\text { parameter }\end{array}$ & $\begin{array}{c}\text { Regular } \\
\text { mode }\end{array}$ & $\begin{array}{c}\text { Adaptive-speed/CAV } \\
\text { mode }\end{array}$ \\
\hline $\begin{array}{c}\text { Spindle motor } \\
\text { temperature } \\
\begin{array}{c}\text { Power consumption } \\
\text { (motor driver) }\end{array}\end{array}$ & $60^{\circ} \mathrm{C}$ & $41{ }^{\circ} \mathrm{C}$ \\
\hline
\end{tabular}

Table 1. Efficiency of the adaptive-speed/CAV algorithm after 40,000 continuous seeks at the ambient temperature of $23^{\circ} \mathrm{C}$. 

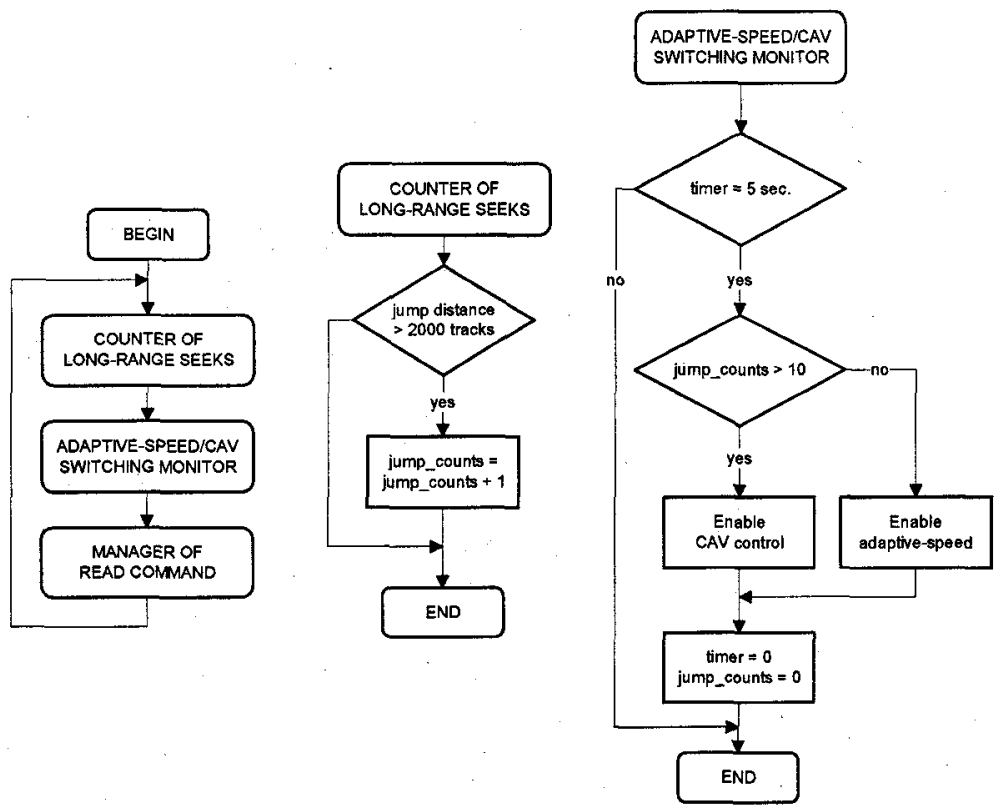

Fig. 2. Flowchart (1/2) of the switching algorithm implemented at the data-path level.

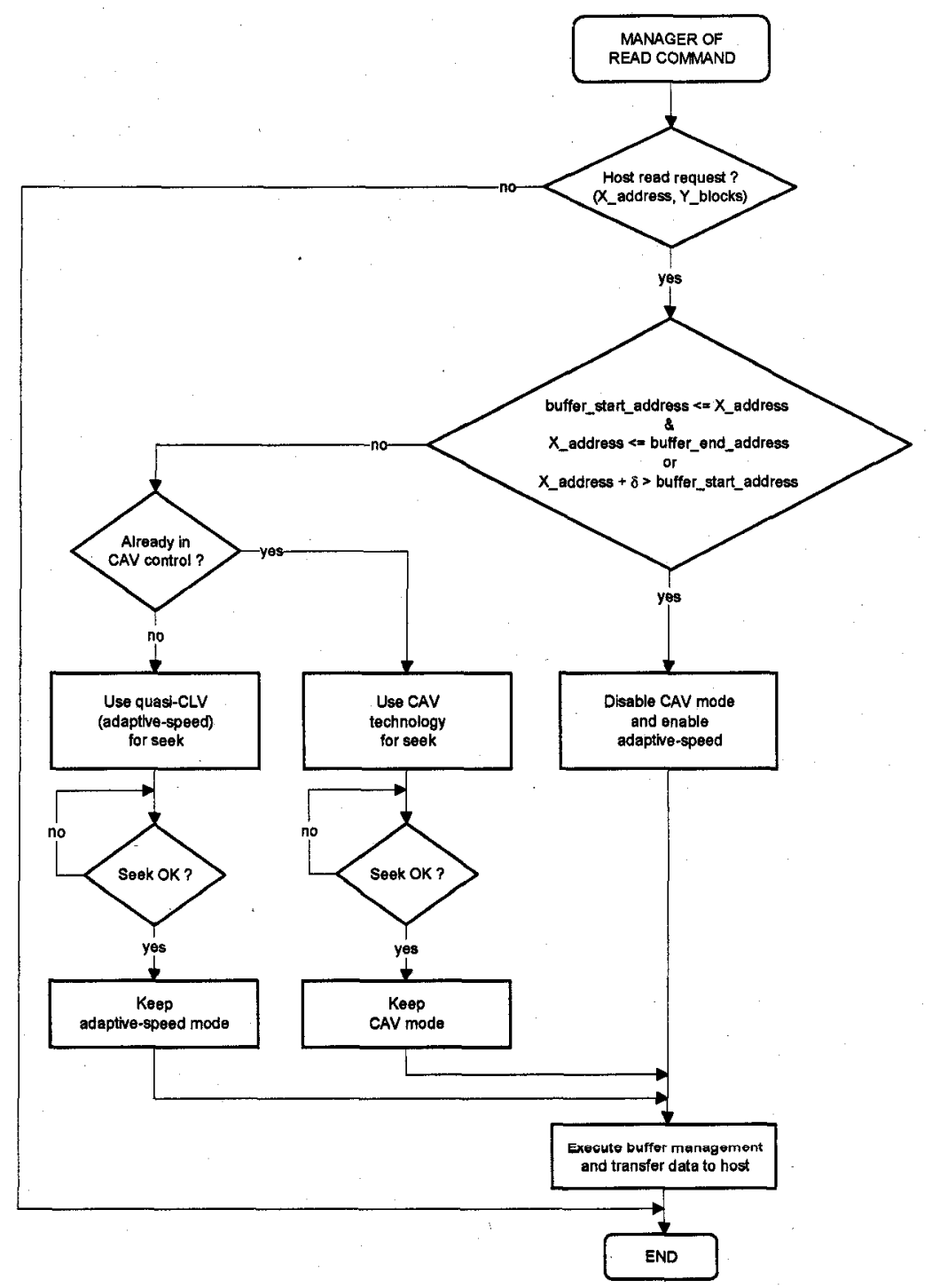

Fig. 3. Flowchart (2/2) of the switching algorithm implemented at the data-path level. 


\section{DISCUSSION}

For the CD-ROM system reported in this paper, the adaptive-speed profile is bordered by the overspeeds $N_{\text {in }}=$ $10 \mathrm{X}$ at the inner disc radius and $N_{\text {out }}=20 \mathrm{X}$ at the outer disc radius, respectively. The profile is optimized [3] such that the maximum overspeed $N_{\max }>N_{\text {out }}$ which can be handled by the system is never exceeded at the end of a random outward-oriented third-stroke seek. The braking possibilities of the spindle motor are also taken into account.

On the other hand, the overspeeds $N_{\text {cav }}$ which occur during continuous-seek are simply radius-dependent and are situated along a pure CAV profile. They satisfy the relation

$$
N_{\text {out }} \frac{R_{\text {in }}}{R_{\text {out }}} \leq N_{\text {cav }}(R)=\frac{2 \pi f_{\text {rot }} R}{\dot{v}_{a}} \leq N_{\text {out }}
$$

where the disc radius $R$ varies between $R_{\text {in }}$ and $R_{\text {out }}$ corresponding to the start and respectively end of the program area and $f_{\text {rot }}$ is the disc rotational frequency. Obviously, when $f_{\text {rot }}$ is properly chosen with respect to all tolerances in the system, the maximum allowed overspeed $N_{\max }$ will never be exceeded during whatever length of a seek.

\section{CONCLUSION}

An algorithm to distinguish the continuous-seek mode from other operating modes is proposed so that a CAV control of the spindle-motor loop can be activated while performing continuous seeks. The data transfer rate of the CD-ROM system during continuous seek is of less importance but the substantial decrease in power consumption within the motor loop represents an important achievement.

\section{REFERENCES}

[1] Stan, S.G. and Bakx, J.L., "Adaptive-Speed Algorithms for CDROM Systems", IEEE Transactions on Consumer Electronics, Vol. 42, No. 1, pp. 43-51, Febr. 1996.

[2] Mee, C.D. and Daniel, E.D., Magnetic Recording. Volume II: Computer Data Storage, McGraw-Hill, Inc., 1988.

[3] Stan, S.G., Kempen, H.van, Lin, C.C.S., Yen, M.S.M., and Wang, W.W., "High-Performance Adaptive-Speed/CAV CDROM Drive", IEEE Transactions on Consumer Electronics, Vol. 43, No. 5, Nov. 1997 (due for publication).

Sorin G. Stan was born in Braşov, Romania, on April 16, 1964. He received a M.Sc. (EE) degree from the Transylvania University at Braşov in 1988 . He worked after graduation at Tohan Mechanical Company, in Romania, where he was involved in various technical projects for the defense industry, especially on the area of measurement systems, data acquisition techniques and electro-hydraulic control. He also received a Master of Electronic Engineering degree from the Eindhoven International Institute of the Eindhoven University of Technology, The Netherlands, in 1992. He joined afterwards Philips Electronics N.V. as a member of the Optical Recording Laboratory of Philips Laser Optics, in Eindhoven. Since 1992 he has carried out development work on CD-ROM systems, specifically aimed to increase the data transfer rate and decrease the access time of the drives. His current research interests include the decoding and servo circuits for $C D$ and DVD systems. Mr. Stan is also pursuing his Ph.D. study at the Eindhoven University of Technology. He is the author and coauthor of several patents and scientific papers.

Henk van Kempen was born in Roggel, The Netherlands, on October 8, 1960. He received his BSc degree in electronic engineering from the Eindhoven Polytechnic School, The Netherlands, in 1984. He joined Philips Electronics N.V. in 1986. From 1986 till 1991 he was a firmware development engineer on professional compact disc players. In 1991 he became a member of the Optical Recording Development Laboratory of Philips Laser Optics in Eindhoven. His work concerned the frmware design and development of CD-Recordable systems. He works since 1993 on firmware control for high-speed CD-ROM systems.

Chi-Cheng Steve Lin was born in Taipei Taiwan on November 6,1957 . He received his BS degree in Applied Physics at Tam-Kang University of Tawan in 1981. In 1983, he joined Tokyo Model Consultant Co. Ltd, at Tokyo, Japan, for model development. In 1984, he worked in Lead Electronics of Taiwan for tooling machine development. Since 1986 he has been involved at Acer in a large variety of product development activities, including pointing devices, mouse and keyboard designs, wireless digitizers, portable copiers, and monitor OSD controllers. Currently he is the hardware team leader responsible for optical recording product development at Acer Peripherals, Inc, Taiwan. Mr. Lin is the principle author of more than 10 patents.

M.-S. Mason Yen was born in Tainan, Taiwan on August 2, 1966. He received his BS and MSEE degrees in Mechanical Engineering from the National Taiwan University in 1988 and 1990 , respectively. After completing his military service he joined the Pollution. Prove Product Corporation for electrical vehicle development. In 1994 he joined the Acer Peripherals, Inc., for optical recording product development where he concentrates on servo control to improve the CD-ROM access performance Currently, he is also pursuing his Ph.D. study at the National Taiwan University. His research interests include actuator servo control and gear backlash investigation in optical recording systems. Mr. Yen is the author and coauthor of more than four technical papers and patents.

Wai W. Wang was born in Taiwan on April 4, 1957. He received his BS Electro-Physics and MS Electro-Optics degrees from National Chiao Tung University of Taiwan in 1980 and 1984, respectively. He also received a MSEE degree from University of New Mexico, Albuquerque, New Mexico, U.S.A: in 1986. In 1987, he joined Optotech Inc. at Colorado Springs, Colorado, USA for optical head and disk drive development. In 1990, he was with Applied Solar Energy Corporation for Laser diode array development. In 1991, he continued his optical recording media research at University of Colorado and received his Ph.D. degree in 1993. During his Ph.D. study, he also worked in Literal Corporatior at Colorado Springs, Colorado, for MO disk drive development until he joined Acer Peripherals, Inc, Taiwan, in March 1994. Since then he has been involved at Acer in optical recording product de. velopment. His research interests include servo control, media, anc optical pick-up. Dr. Wang was the principle author for more than 1 : technical publications and patents. 